\title{
PENHASCOS DE ATIVIDADE BIOLÓGICA COMO FERRAMENTA NA ANÁLISE DA RELAÇÃO ESTRUTURA ATIVIDADE EM UMA SÉRIE DE INIBIDORES DA ENZIMA $\beta$-CETOACIL-ACP SINTASE III
}

\author{
A.C.S. XAVIEL ${ }^{1}$, R.A.A. SANTOS ${ }^{2}$ e E.G. BARBOSA ${ }^{3}$ \\ 1,2,3 Universidade Federal do Rio Grande do Norte, Centro de Ciências da Saúde, \\ Departamento de Farmácia. \\ E-mail para contato: xaviel.amanda@gmail.com
}

RESUMO - A sintese de ácidos graxos, principalmente pela enzima $\beta$-cetoacilACP sintase III (FabH), vem despontando como um excelente alvo para novas moléculas com ação antimicrobiana. Porém, apesar da urgência gerada pela crescente resistência bacteriana, a síntese de novas moléculas se mostra uma tarefa bastante dispendiosa tanto em tempo como em recursos financeiros. Neste sentido, utilizar-se das informações contidas nos ligantes, já sintetizados, para extrair o máximo de informações da afinidade pelos receptores, configura-se como uma alternativa de baixo custo operacional. Desta forma, utilizou-se de ferramentas computacionais para desenho e análise das interações do receptor FabH com as 233 moléculas selecionadas com $I_{50}$ definidos, as mesmas foram testadas contra cepas de E. coli. Percebeu-se que são as pequenas diferenças em moléculas bastante similares que melhor definem as regiões da molécula e do inibidor, que mais contribuem com a atividade biológica. A relação entre este grupo de moléculas é conhecida como penhascos de atividade biológica. A partir deste estudo evidenciou-se que o ligante deve ser capaz de atingir o sitio catalítico de reação e interagir através de forças polares com o mesmo, principalmente com a Cisteína 112, Asparagina274 e Histidina244(tríade catalítica), além de que seus substituintes devem promover maior tempo de interação com os aminoácidos citados, informações importantes que podem ser exploradas para o desenvolvimento de novos inibidores.

Palavras chave: FabH, SAR, desenho de inibidores

ABSTRACT: The synthesis of fatty acids, mainly by the enzyme $\beta$-ketoacyl-ACP synthase III (FabH), has been emerging as an excellent target for new molecules with antimicrobial activity. However, despite the urgency generated by the increasing bacterial resistance, the synthesis of new molecules is a very expensive task both in time and in financial resources. In this sense, using the information provided by know ligands could reduce the cost designing better inhibitors. In this way, computational tools were used to design and analyze the interactions of the 
FabH receptor with the 233 molecules selected with defined $I C_{50}$, they were tested against strains of $\underline{E}$. coli. It has been found that the small differences in molecules define the regions that contribute with the biological activity. The relationship between this group of molecules is known as activity cliffs. From this study it was evidenced that the ligand should be able to reach the catalytic reaction site and interact through polar interactions with Cysteine 112, Asparagine 274 and Histidine 244(catalytic triad) besides that, its substituents should promote a longer time of interaction with the mentioned amino acids. Such knowledge can be explored for the development of new inhibitors.

Keywords: FabH, SAR, inhibitors design.

\section{INTRODUÇÃO}

Os lipídeos são o maior componente da membrana plasmática bacteriana, pois constituem estruturas fundamentais a sua formação, como fosfolipídios e lipopolissacarídeos. Estes constituintes, além de um papel estrutural, formam um arcabouço para as propriedades biofísicas da membrana (LU et al., 2004). A síntese de ácidos graxos em mamíferos acontece através de uma única enzima multifuncional, a ácido graxo sintase (FAS) (WHITE et al., 2005). O mecanismo alternativo de síntese de ácidos graxos, ou FAS II, é encontrado em bactérias, parasitas e plantas. Diferentemente do mecanismo encontrado em mamíferos, o FAS II utiliza-se da combinação de diversas enzimas, com atividades distintas, e seu produto final não se restringe apenas ao palmitato, podendo sintetizar uma diversidade de ácidos graxos (WHITE et al.,2005) (ZHANG et al., 2006). A partir da necessidade de desenvolver novos antimicrobianos esta rota metabólica bacterina vem despontando com um potencial alvo para a síntese de novas moléculas. A enzima $\beta$-cetoacil-ACP sintase III (FabH) se destaca como principal alvo (WHITE et al., 2005) a qual é vital para a síntese de ácidos graxos.

Umas das ferramentas que pode ser utilizada para o desenho de novos ligantes é a análise de penhascos de atividade (AC, do inglês activity cliffs). Os estudos AC baseiam-se na investigação dos impactos drásticos da potência de modificações estruturais mínimas (STUMPFE; BAJORATH, 2012). Há dois critérios fundamentais na definição de um par de AC: o primeiro a similaridade entre duas moléculas e o segundo a diferença de atividade biológica (BAJORATH, 2017). Esta similaridade costuma ser categorizada entre similaridade 2D e similaridade 3D (MAGGIORA et al., 2014). A comparação entre a similaridade das moléculas pode ser feitas através de uma série de metodologias como Tanimoto e Cosine (HOLLIDAY et al., 1995), Hamming (WILLETT et al., 1998) entre outros, sendo que o coeficiente de Tanimoto é o mais amplamente utilizado (WILLETT, 2006). Quando duas moléculas possuem alta similaridade e grande diferença de atividade biológica tem um AC. Um índice utilizado para medir AC é o Structure activity landscape Index (SALI) (GUHA; VAN DRIE, 2008).

O presente estudo tem por objetivo realizar estudos de AC, utilizando o coeficiente de Tanimoto para calcular a similaridade e gerar informações sobre as regiões que mais contribuem com a atividade biológica, para posteriores planejamentos de novos inibidores de FabH. Tais inibidores podem ser úteis para o tratamento de infecções bacterianas causadas por agentes multirresistentes. 


\section{MATERIAIS E MÉTODOS}

Após realizar uma análise preliminar na literatura, foram escolhidas 233 moléculas de 16 artigos ((LI et al., 2009; LI et al., 2010; LI et al., 2012; LI et al., 2013; LI et al., 2014; ALHAMADSHEH et al., 2007; ALHAMADSHEH et al., 2008; LV et al., 2010; YANG et al.,2012; SONG et al., 2014; WANG et al., 2012; LI et al., 2014; MCKINNEY et al., 2016; CHENG et al., 2009; CHENG et al., 2010; CHENG et al., 2013; ZHANG et al., 2011) para compor o grupo de moléculas para estudo dos AC. Cada uma das 233 moléculas foi desenhada com o software livre MarvinSketch versão 15.9 (ChemAxon, 2017). O estado de protonação adotado no desenho das moléculas considerou o pH dos experimentos in vitro. Para a análise da interação entre as moléculas e o receptor foram selecionadas duas estruturas cristalográficas do Protein Data Bank (BERMAN, et al., 2000) de códigos 5BNS e 5BNR ( MICKNNEY et al., 2016). Estas estruturas forneceram as conformações bioativas da enzima com seus respectivos ligantes complexados ao sítio ativo.

A similaridade 2D foi aferida através do software Open babel 2.4.1 (O'BOYLE et al., 2011) utilizando-se do cálculo da similaridade de Tanimoto. Os pares foram submetidos ao cálculo do SALI (Equação 1).

$$
S A L I=\frac{\left(A B_{a}-A B_{b}\right)}{\left(1.01-S I M_{a b}\right)}
$$

onde $\mathrm{AB}_{\mathrm{a}}$ e $\mathrm{AB}_{\mathrm{b}}$ é atividade biológica de duas moléculas a e b e $\mathrm{SIM}_{\mathrm{ab}}$ é a similaridade entre as duas moléculas a e $b$.

As moléculas foram comparadas quanto a sua estrutura 2D, a partir destas informações foram construídas uma planilha de atividade versus similaridade com o intuito de verificar moléculas muito similares, mas com grande diferença de atividade biológica. Os pares ou grupos de moléculas obtidos foram visualizados através do software Gephi 0.9.29 (BASTIAN M., HEYMANN S., JACOMY M., 2009).

As moléculas escolhidas foram alinhadas segundo as enzimas selecionadas e analisadas através do programa Protein-Ligand Interaction Profiler (SALENTIN et al., 2015). A partir da análise destes pares e suas interações com a enzima alvo poderemos identificar regiões essenciais ao funcionamento do sítio ativo ou visualizar novas regiões de interação ou ainda regiões que limitam a ação farmacodinâmica.

\section{RESULTADOS E DISCUSSÃO}

Após aplicar a regra SALI obteve-se a relação entre todas as moléculas, porém somente valores de SALI superiores a 6,7 foram considerados. Dois grupos foram escolhidos para a interpretação dos AC. A molécula acs22016_28 esteve presente nos dois grupos. O grupo 01 é formado pelas moléculas acs22016_41, acs22016_27 e acs22016_28 (Figura 01).

Analisando a interação destas moléculas com o sítio ativo percebe-se que todas as moléculas compartilham interações em comum, as quais são feitas com a tríade catalítica 
(Cisteína 112, Asparagina274 e Histidina244). A ausência do substituinte hidroximetil na posição meta da molécula acs22016_27 é grandemente lesiva a esta interação (Figura 2. acs22016_28 acs22016_27) que provavelmente é o responsável pela diminuição da atividade inibitória em 100 vezes, mesmo que as moléculas sejam altamente similares (AC).

Figura 1 - Agrupamento em linha

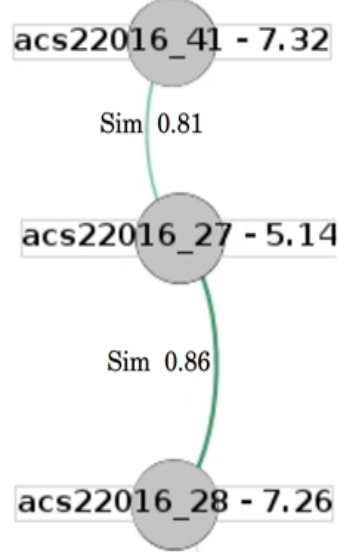

Sim 0.78

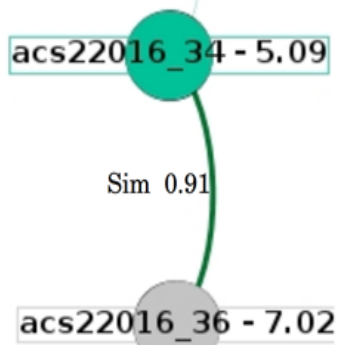

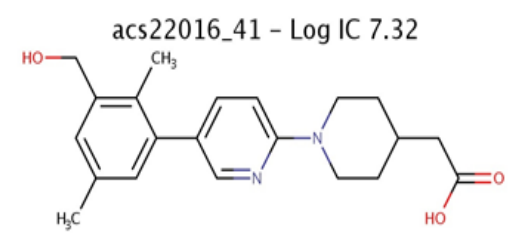
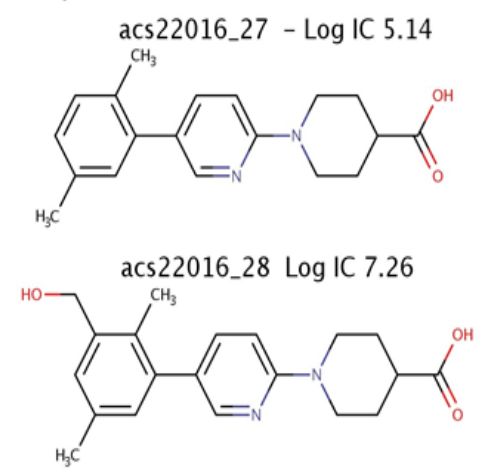

acs22016_34 - Log IC 5.09

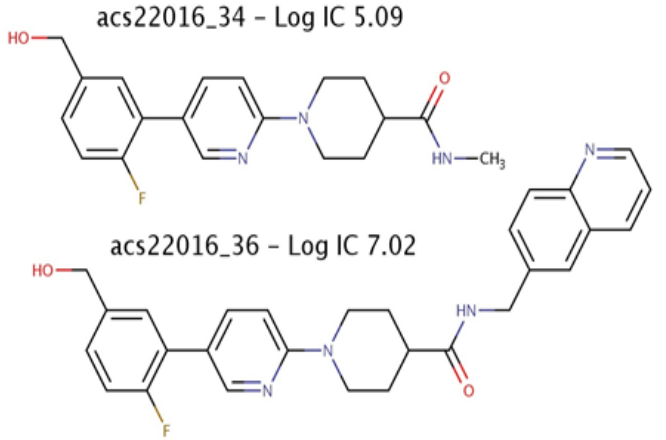

Fonte: Elaborada pelo autor

Figura 2 - Interação com o sítio ativo, Grupo 01.

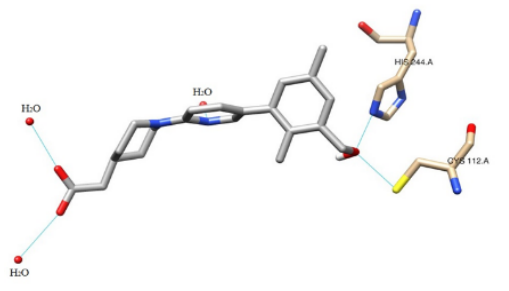

acs22016_41

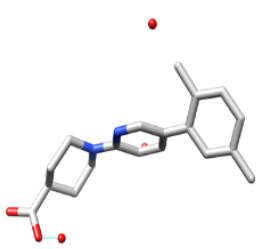

acs22016_27

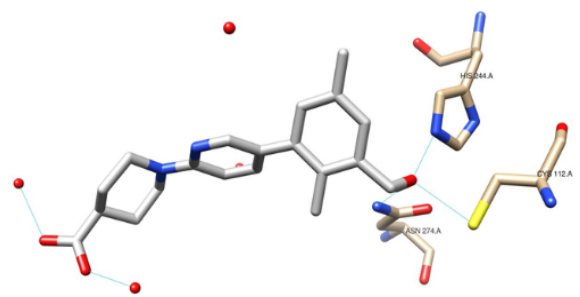

acs22016_28

Fonte: Elaborada pelo autor

O segundo grupo formado pelas moléculas acs22016_28, acs22016_34, e acs22016_36 (Figura 1) conserva o mesmo esqueleto, mas com alterações nos 
substituintes nos dois sentidos da cadeia conferindo a capacidade de realizar interações iônicas ou explorar sítios hidrofóbicos. A molécula acs22016_28 é capaz de realizar Ligação iônica ou ponte salina com resíduo de arginina (ARG151) já a molécula acs22016_34 não pode realizar tal interação devido à substituição por uma amida secundária (Figura 3).

Figura 3: Interações com o sítio ativo

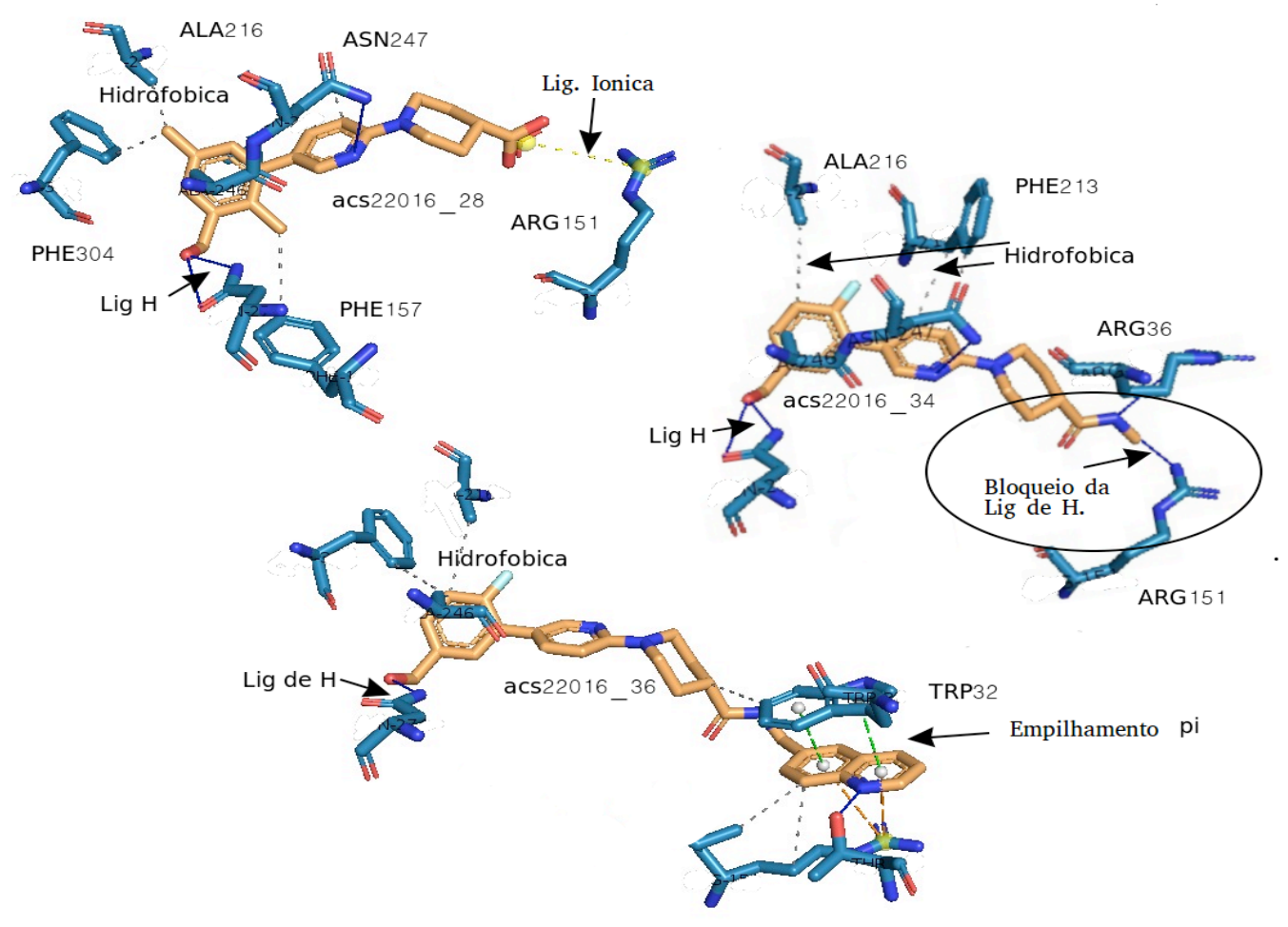

Fonte: Elaborada pelo autor

Quanto ao par formado entre as moléculas acs22016_34 e acs22016_36 a amida secundária é substituída por um anel quinolina. Tal alteração faz com que a molécula alcance um novo bolso de interação onde o substrato natural acetil-CoA interage. $\mathrm{O}$ núcleo quinolina realiza ligações tipo cátion- $\pi$ ou empilhamento- $\pi$ e uma ligação de hidrogênio (Figura 3). Ao realizar as interações descritas a molécula acs22016_36 alcança valores de atividade similar à molécula acs22016_28.

\section{CONCLUSÃO}

Os ligantes mais potentes devem ter tamanho e formato que os propiciem atingir a região mais profunda do sítio ativo, composto pela tríade catalítica da enzima FabH, e quando diante desta pode interagir através de ligações de hidrogênio com um ou mais dos aminoácidos que compõem esta tríade. A possibilidade de formar pontes salinas com os 
aminoácidos aparenta gerar um ganho na ação inibitória do ligante quando comparado com a formação de ligações de hidrogênio, porém aparenta ter menor importância quando comparado a formação de ligações hidrofóbicas no bolso lateral. Diante do exposto concluísse que o "inibidor ideal" deve ser capaz de interagir com a tríade catalítica e realizar interações apolares com aminoácidos presentes na região do sítio ativo e ligações empilhamento- $\pi$ para obter o máximo de atividade biológica.

\section{REFERÊNCIAS}

ALHAMADSHEH, M. M. et al. Synthesis and biological evaluation of thiazolidine-2one 1,1-dioxide as inhibitors of Escherichia coli ??-ketoacyl-ACP-synthase III (FaH). Bio. and Med. Chem. L, v. 17, n. 4, p. 879-883, 2007.

ALHAMADSHEH, M. M. et al. Synthesis and biological evaluation of novel sulfonylnaphthalene-1,4-diols as FabH inhibitors, Bio. and Med. Chem. L v. 18, n. 24, p. 6402 6405, 2008.

BAJORATH, J. Representation and identification of activity cliffs. Expert Opinion on Drug Discovery, v. 12, n. 9, p. 1-5, 2017.

BASTIAN M., HEYMANN S., JACOMY M. Gephi: an open source software for exploring and manipulating networks. International AAAI Conference on Weblogs and Social Media. 2009.

ChemAxon- MarvinSketch 15.9, Disponível em < http://www.chemaxon.com>, Acessado em 01 de Novembro, 2017.

CHENG, K. et al. Synthesis, antibacterial activities and molecular docking studies of peptide and Schiff bases as targeted antibiotics. Bio. and Med. Chem, v. 17, n. 23, p. 7861-7871, 2009

CHENG, K. et al. Synthesis, molecular modeling and biological evaluation of PSB as targeted antibiotics Bio. and Med. Chem., v. 18, n. 7, p. 2447-55, 2010.

CHENG, K.; XUE, J. Y.; ZHU, H. L. Design, synthesis and antibacterial activity studies of thiazole derivatives as potent ecKAS III inhibitors. Bio. and Med. Chem. L, v. 23, n. 14, p. 4235-4238, 2013.

GUHA, R.; VAN DRIE, J. H. Structure - Activity landscape index: Identifying and quantifying activity cliffs. Journal of Chemical Information and Modeling, v. 48, n. 3, p. 646-658, 2008.

BERMAN, H.M. et al. The Protein Data Bank, Nucleic Acids Research, 28: 235-242, 2000.

HOLLIDAY, J. D.; RANADE, S. S.; WILLETT, P. A fast algorithm for selecting sets of dissimilar structures from large chemical databases . Quanti. Struct.-Activ R., v. 14, p. 501-506, 1995.

LI, H. Q. et al. Synthesis of C(7) modified chrysin derivatives designing to inhibit $\beta$ ketoacyl-acyl carrier protein synthase III (FabH) as antibiotics. Bio. and Med. Chem, v. 17, n. 17, p. 6264-6269, 2009. 
LI, H. Q. et al. Design and synthesis of novel deoxybenzoin derivatives as FabH inhibitors and anti-inflammatory agents. Bio. and Med. Chem. L, v. 20, n. 6, p. 2025-2028, 2010.

LI, Y. et al. Design, synthesis and antimicrobial activities of nitroimidazole derivatives containing 1,3,4-oxadiazole scaffold as FabH inhibitors. Bio. and Med. Chem, v. 20, n. 14, p. 4316-4322, 2012.

LI, Y. et al. Design, synthesis and antimicrobial activities evaluation of Schiff base derived from secnidazole derivatives as potential FabH inhibitors. Bioorganic and Medicinal Chemistry, v. 21, n. 11, p. 3120-3126, 2013.

LI, J. R. et al. Design and synthesis of thiazole derivatives as potent FabH inhibitors with antibacterial activity. European Journal of Medicinal Chemistry, v. 75, p. 438-447, 2014.

LV, P.-C. et al. Design, synthesis, and structure-activity relationships of pyrazole derivatives as potential FabH inhibitors. Bio. and Med. Chem. L., v. 20, n. 15, p. 46574660, 2010.

LU, Y.-J.; ZHANG, Y.-M.; ROCK, C. O. Product diversity and regulation of type II fatty acid synthases. Biochemistry and cell biology $=$ Biochimie et biologie cellulaire, v. 82, n. 1, p. 145-155, fev. 2004.

MAGgiora, G. et al. Molecular similarity in medicinal chemistry. J. of Med. Chem., v. 57, n. 8, p. 3186-3204, 2014.

MCKINNEY, D. C. et al. Antibacterial FabH Inhibitors with Mode of Action Validated in Haemophilus Influenzae by in vitro Resistance Mutation Mapping. ACS Infectious Diseases, p. acsinfecdis.6b00053, 2016.

O'BOYLE, N. M. et al. Open Babel: An Open chemical toolbox. Journal of Cheminformatics, v. 3, n. 10, p. 1-14, 2011.

SALENTIN, S. et al. PLIP: Fully automated protein-ligand interaction profiler. Nucleic Acids Research, v. 43, n. W1, p. W443-W447, 2015.

SONG, X. et al. Synthesis and Antibacterial Activity of Cinnamaldehyde Acylhydrazone with a 1,4-Benzodioxan Fragment as a Novel Class of Potent $\beta$-Ketoacyl-Acyl Carrier Protein Synthase III (FabH) Inhibitor. Chem. and Pharm B., v. 62, n. 11, p. 1110-1118, 2014.

STUMPFE, D.; BAJORATH, J. Exploring activity cliffs in medicinal chemistry. J. of Med. Chem, v. 55, n. 7, p. 2932-2942, 2012.

WANG, X. L. et al. Design, synthesis and antibacterial activities of vanillic acylhydrazone derivatives as potential $\beta$-ketoacyl-acyl carrier protein synthase III (FabH) inhibitors. Euro. J. of Med. Chem, v. 57, p. 373-382, 2012.

WHITE, S. W. et al. The structural biology of type II fatty acid biosynthesis. Annual review of biochemistry, v. 74, 2005.

WILLETT, P. Similarity-based virtual screening using 2D fingerprints. Drug Discovery Today, v. 11, n. 23-24, p. 1046-1053, 2006.

WILLETT, P.; BARNARD, J. M.; DOWNS, G. M. Chemical Similarity Searching. J. of 
Chem. Inform. and Comp. Sciences, v. 38, n. 6, p. 983-996, 1998.

YANG, Y. S. et al. Discovery and modification of sulfur-containing heterocyclic pyrazoline derivatives as potential novel class of $\beta$-ketoacyl-acyl carrier protein synthase III (FabH) inhibitors. Bio. and Med. Chem. L., v. 22, n. 14, p. 4619-4624, 2012

ZHANG, Y.-M.; WHITE, S. W.; ROCK, C. O. Inhibiting bacterial fatty acid synthesis. The J. of bio. Chem., v. 281, n. 26, p. 17541-17544, jun. 2006.

ZHANG, H. J. et al. Synthesis, molecular modeling and biological evaluation of ??ketoacyl-acyl carrier protein synthase III $(\mathrm{FabH})$ as novel antibacterial agents. Bio. and Med. Chem, v. 19, n. 15, p. 4513-4519, 2011. 